Bangladesh Journal of Neuroscience 2019; Vol. 35 (1): 27-32

\title{
Vascular Imaging Based Subtyping of Ischemic Stroke in BSMMU
}

\author{
SHAHIDULLAH M ${ }^{1}$, DEY $\mathrm{SK}^{2}$, AHMED $\mathrm{A}^{3}$, DAS $\mathrm{P}^{4}$, SULTANA $^{5}$
}

\begin{abstract}
:
Background: Most strokes and stroke related death \& disability happened in low and middle income countries. The clinician should be familiar with the sub typing of ischemic stroke patients and the risk factors analysis. Vascular imaging is necessary for classifying the patient. The main objective of this study was to evaluate the subtype of ischemic stroke patients and risk factor analysis of different etiology. Method: This is a hospital based prospective study in Bangladesh. Within the time frame of 2014 March to 2017 November; we analyzed 1978 patients of ischemic stroke within 10 days of symptom onset. Among them 877 patients have been selected for this study to whom brain imaging (CT/MRI), vascular imaging (MRA, DSA), ECG and echocardiography have been done. We did subtyping according to TOAST criteria. Results: The mean age of patients was $60.5 \pm 11$ years with $70.47 \%$ subjects male and $29.53 \%$ female. Within the classification of TOAST, we have found $43.87 \%$ of patients were in large artery atherosclerosis group, $23.83 . \%$ in small vessel occlusion group, $8.46 \%$ in cardiac embolism group, $19.30 \%$ in undetermined etiology group and $4.54 \%$ in other determined etiology. Among risk factors hypertension in $58.15 \%$, DM was found in $38.42 \%$, hypercholesterolemia in $38.88 \%$ of patients. Hypertension was significantly high in large artery atherosclerosis group. Conclusion: In ischemic stroke patients, large artery atherosclerosis was the most common subtype and hypertension was significant in this group.
\end{abstract}

Keywords: Ischemic stroke, Subtype, TOAST criteria, Risk factor, HTN

Introduction:

Worldwide stroke is the second most common cause of death ${ }^{1}$ and the most known cause of severe disability ${ }^{2}$. Strokes can be classified into ischemic and hemorrhagic types ${ }^{3}$. Worldwide about $69 \%$ of stroke, $71 \%$ of stroke death and $78 \%$ of DALYs lost occurred in low-income and middleincome countries. Globally there was $25 \%$ increase in incidence of people ranging from 20-64 years of age, $23 \%$ increase in prevalence in high income countries, increase mortality rate in south Asia within 1990 to $2010^{4}$. Prevalence rate of stroke in Bangladesh is around $0.3 \%{ }^{5}$. Ischemic stroke is a heterogeneous disorder and there are multiple mechanisms for it ${ }^{6}$. Pathophysiologically ischemic stroke may occur due to thrombosis of large or small vessels, emboli from heart or artery, hypoperfusion in watershed area or border zone ${ }^{7}$. In western population cardioembolic stroke is the dominant cause, in India large artery atherosclerosis and in Pakistan lacunar stroke is the most common cause of ischemic stroke ${ }^{8}$. Among the important risk factors are uncontrolled hypertension, dyslipidaemia, diabetes mellitus, coronary artery disease, atrial fibrillation, smoking and those vary with stroke subtypes ${ }^{9,10}$.

The Trial of Org 10172 in Acute Stroke Treatment (TOAST) classification was introduced in 1993 to classify ischemic stroke according to mechanism of ischemia. It is divided into 5 groups: large artery atherosclerosis (LAA), cardikoembolism (CE), small vessel occlusion (SVO), stroke of other

1. Dr. Md. Shahidullah, Associate Professor, Department Of Neurology, BSMMU

2. Dr. Subash Kanti Dey, Associate Professor, Department Of Neurology, BSMMU

3. Dr. Anis Ahmed, Assistant Professor, Department Of Neurology, BSMMU

4. Dr. Panchanan Das, Associate Professor, Department Of Neurology, Cumilla Medical College

5. Prof. Dr. Nahid Sultana, Professor, Department Of Community Medicine, Dhaka National Medical College 
determined etiology (SODE), stroke of undetrermined etiology (SUDE) ${ }^{11}$. In retrospective study TOAST classification had been proven as valid and reliable ${ }^{12}$. Many studies had been done to identify the risk factors in each sub types in different community. There is a little data regarding ischemic stroke subtypes and their risk factors in Bangladeshi people. We wanted to know the common etiology, subtypes and risk factors of each subtypes in ischemic stroke.

\section{Methods:}

This was a prospective, cross-sectional study conducted in Bangabandhu Sheikh Mujib Medical University (BSMMU), Dhaka which is a tertiary care hospital and post graduate institute. We took medical data of hospitalized patients in neurology department from March 2014 to November 2018. We defined stroke according to WHO criteria as features of focal and global cererbral dysfunction that lasting for more than 24 hours with no other than vascular cause. Any ischemic stroke patients of more than 18 years of age and within 10 days of symptom onset, willing to be included were enrolled in this study. Any TIA, venous stroke or hemorrhagic stroke patients were excluded for enrollment. After clinical examination brain imaging (CT/ MRI), ECG, ehocardiography and vascular imaging (MRA/ CTA, cerebral DSA) had been advised in all patients. As financial matters have to be paid by patient himself so all patients were not able to do all investigations necessary for the sub typing of ischemic stroke. They did duplex study of neck vessels as vascular imaging but they were not included in this study. Total 1978 ischemic stroke patients were enrolled but only 677 had been selected for this study. Sub typing of ischemic stroke into 5 categories were done according to the TOAST criteria ${ }^{11}: 1$. Largeartery atherosclerosis - LAA, diagnosed by clinical features of cortical dysfunction and criteria of vascular imaging that is $>50 \%$ stenosis or occlusion of major artery or cortical artery; 2. Cardioembolism- CE, diagnosed by major risk factors for embolism at least one and no apparent evidence of other subtypes; 3. Small-vessel occlusion - SVO, diagnosed by clinical features of lacunar syndrome with no cortical features and lesion in brain imaging should be $<1.5 \mathrm{~cm}$; 4 . Stroke of other determined etiology- SODE, diagnosed by other evidence of stroke risk factors as hypercoagulability, evidence of vasculitis, dissection, moya-moya found in vascular imaging; 5. Stroke of undetermined etiology- SUDE, diagnosed by when two or more causes were identified. Sub typing was done after all documents were available to the patient. Statistical analysis was performed using software SPSS for windows. Numerical data is presented as mean \pm standard deviation (SD) and risk factors and sub typing are presented as percentages. Chi-square \& Fisher's exact test was done to compare between qualitative data. Analysis was defined significant when $p$ - value is $<0.05$.

\section{Results:}

We enrolled 1978 patients of ischemic stroke within 10 days of symptom onset. Among them 877 patients had been selected for this study to whom brain imaging (CT/MRI), vascular imaging (MRA, DSA), ECG and echocardiography had been done. Of all 877 patients, $542(61.78 \%)$ were male and $335(36.22 \%)$ were female. The mean age of patients was $60.5 \pm 11$ years.

Table-I

Distribution of respondents by age and gender

Distribution of respondents by age and gender

\begin{tabular}{lcc} 
Age Group & Number & Percentage \\
$<30$ & 41 & $4.67 \%$ \\
$30-40$ & 76 & $8.67 \%$ \\
$41-50$ & 170 & $19.33 \%$ \\
$51-60$ & 257 & $29.33 \%$ \\
$61-70$ & 207 & $23.67 \%$ \\
$>70$ & 126 & $14.33 \%$ \\
Total & 877 & $100 \%$ \\
By gender & & \\
Male & 618 & $70.47 \%$ \\
Female & 259 & $29.53 \%$ \\
Total & 877 & $100 \%$ \\
\hline
\end{tabular}


Table-II

The subtype of Ischemic Stroke

\begin{tabular}{lcc}
\hline Category & Number of patients & Percentage \\
\hline Large-artery atherosclerosis (LAA) & 385 & $43.87 \%$ \\
Cardio-embolism (CE) & 74 & $8.46 \%$ \\
Small-vessel occlusion (SVO) & 209 & $23.83 \%$ \\
Stroke of other determined etiology (SODE) & 40 & $4.54 \%$ \\
Stroke of undetermined etiology (SUDE) & 169 & $19.30 \%$ \\
\hline Total & 877 & $100 \%$ \\
\hline
\end{tabular}

Table-III

Risk factors of different etiology

\begin{tabular}{lcccc}
\hline Category & Previous H/O stroke & DM & HTN & DL \\
\hline LAA $n=385$ & $53(13.77 \%)$ & $178(46.23 \%)$ & $318(82.59 \%)$ & $189(49.09 \%)$ \\
CEn=74 & $6(8.1 \%$ & $3(4.05 \%)$ & $10(13.51 \%)$ & $9(12.16 \%)$ \\
SVOn= 209 & $12(5.74 \%)$ & $90(43.06 \%)$ & $87(41.62 \%)$ & $77(36.84 \%)$ \\
SODEn= 40 & $3(7.5 \%)$ & $5(12.5 \%)$ & $4(10 \%)$ & $7(17.5 \%)$ \\
SUDEn $=169$ & $17(10.09 \%)$ & $61(36.09 \%)$ & $91(53.84 \%)$ & $59(34.92 \%)$ \\
Total $(n=877)$ & $94(10.37 \%)$ & $337(38.42 \%)$ & $510(58.15 \%)$ & $341(38.88 \%)$ \\
p value & .962 & .201 & $.005^{*}$ & .201 \\
\hline
\end{tabular}

Most patients (29.23\%) belonged to the age group $51-60$, followed by $23.67 \%$ from $61-70$ age groups. A total $67.33 \%$ was above the age of 50 . The most common stroke subtypes was large artery atherosclerosis LAA $(n=385,43.87 \%)$, followed by small vessel occlusion SVO $(n=209,23.83 \%)$, Stroke of undetermined etiology SUDE $(n=169$, $19.30 \%)$, Cardio-embolism CE ( $n=74,8.46 \%)$, Stroke of other determined etiology SODE $(n=40$, $4.54 \%)$.

About risk factors, hypertension was found in $(n=510,58.15 \%)$ patients followed by dyslipidaemia $(n=341,38.88 \%)$ and diabetic mellitus $(n=337$, $38.42 \%$ ). Among the risk factors, hypertension was significantly high ( $n=318,82.59 \%$ of 385$)$ in large artery atherosclerosis group which was significant, followed by stroke of undetermined etiology ( $n=91$, $53.84 \%$ of 169 ). Diabetes mellitus was also high in large artery atherosclerosis group $(n=178$, $46.23 \%$ of 385 ), followed by small vessel occlusion $(n=90,43.06 \%$ of 209$)$.

\section{Discussion:}

Our goal was to know the sub typing of ischemic stroke and risk factor of each subtype according to TOAST criteria. It is commonly used classification system that uses clinical feature, brain imaging findings, and vascular imaging plus some ancillary test. It is the largest single center study about sub typing of ischemic stroke in Bangladesh. 877 patients had been selected for the study among 1978 patients as rest of the patients did not get the opportunity to do basic investigations for enrollment. This study finds male predominance than female in ischemic stroke and almost two thirds of patients are above the age of 50 . Renjen $\mathrm{PN}$ and his associates ${ }^{10}$ found male is greater than female in India. Bhowmik NB et al. ${ }^{13}$ found $(67.7 \%)$ in Bangladesh, Shakya D and associates ${ }^{14}$ found $(51.1 \%)$ in Nepal. The finding is also similar in developed countries. A study of 1136 patients done by Caso $\mathrm{V}$ et al. ${ }^{15}$ found female was lesser than $(46 \%)$ male. Marija B et al. ${ }^{16}$ found female 
dominance $(52 \%)$ in their study, but they took both ischemic and hemorrhagic stroke including $\mathrm{SAH}$ in their study. The mean age of this present study was $60.5 \pm 11$ years which was comparable to the study done by Renjen PN and associates ${ }^{10}$. A study of 2450 patients done by Bouzidi and associates ${ }^{17}$ found mean age was 63.2, and another of 679 patients done by Bhowmik NB et al. ${ }^{13}$ found 60.4 years. In Nepal mean age was 63.2 years done by Shakya D and associates ${ }^{14}$. However in Europe Caso $\mathrm{V}$ et al. ${ }^{15}$ found mean age as $72.68( \pm 13.27)$.

This study finds large artery atherosclerosis (LAA) is the most common sub type as $43.67 \%(n=385)$. Kaul S et al. ${ }^{18}$ found $37.6 \%$ as LAA in India of total 2072 patients similar to our findings. Again a study conducted in Singapore by Dev Silva et al. within South Asian population found $41 \%$ as $\operatorname{LAA}^{19}$. Wong LK found $47 \%$ in Thailand, Harris $S$ et al. ${ }^{20}$ found $59.6 \%$ in Indonesia, as LAA. Also in Chinese population the result was similar as $37.4 \%$ done by Tan YF ${ }^{21}$. In India study done by Shubhakaran KP 22 and Raghuvanshi $S^{23}$ showed also similar result. In contrary, Kolominsky-Raba PL et al. ${ }^{24}$ Kang DW et al. ${ }^{25}$ Aquil $\mathrm{N}$ et al. ${ }^{26}$ found $15.3 \%, 16.28 \%, 31 \%$ ischemic stroke patients as LAA respectively. This variation could be due to ethnic origin. More cerebral DSA in our study population can be one explanation for finding more LAA as there are facility to do cerebral DSA in our department and MRA or CTA is more expensive than DSA.

In our analyses small vessel occlusion (SVO) were $23.83 \%$ which was the second most common sub type. Most of the studies done in this sub continent and south Asia found comparable result like this study. Kaul S et al ${ }^{18}$ and Raghuvanshi $S^{23}$ in India, Zafar et al. ${ }^{8}$ in Pakistan, Harris $S$ et al. ${ }^{20}$ in Indonesia found $19.9 \%, 17.24 \%, 27.7 \%$ respectively. Murthy Raju ISSVP ${ }^{27}$ Kaul $S^{28}$ also found similar result in their study like $23.4 \%$ and $18 \%$ respectively. In developed countries the percentage of SVO is somewhat higher than in this study. Biswas $\mathrm{M}^{29}$ in USA, Ihle-Hansen $\mathrm{H}$ et al. ${ }^{30}$ in Norway, Wu CY ${ }^{31}$ in Taiwan, De silva DA ${ }^{19}$ in Singapore found $45.2 \%, 31.4 \%, 39.4 \%, 35 \%$ respectively. Aquil $\mathrm{N}^{26}$ in Pakistan got $43 \%$ in their study that is higher than this study.
We found $8.46 \%$ of total ischemic stroke patients as cardio embolism (CE) similar to other study done in this sub continent like Aquil $\mathrm{N}$ et al. ${ }^{26}$ and Syed NA et al. ${ }^{32}$ in Pakistan as $8 \%$ and $6 \%$ rspectively, Kaul $\mathrm{S}$ et $\mathrm{al}^{18}$ \& Shubhakaran $\mathrm{KP}^{22}$ in India as $10 \%$ both . Contrary, Kolominsky-Raba PL et al. ${ }^{24}$ found CE as $27 \%$, Kang DW et al. ${ }^{25}$ as $40.59 \%$, Ihle-Hansen $\mathrm{H}$ et al. ${ }^{30}$ as $31.4 \%$. This may be due to different population origin and the increased rate of cardiac disease, more extensive work like ECG, Echocardiography, Holter monitoring, Transesophageal echocardiography and less cerebral angiography for evaluation of ischemic stroke patients.

In this study hypertension was the most common risk factor $(58.15 \%)$ followed by dyslipidaemia $(38.88 \%)$ and diabetes (38.42\%). This is consistent with the other srudy in this subcontinent. In Pakistan Zafar F et al. ${ }^{8}$, Sharif $\mathrm{F}$ et al. ${ }^{33}$, Taj $\mathrm{F}$ et al. ${ }^{34}$ and in India Pathak A. et al. ${ }^{35}$ found hypertension $62.7 \%$, $71 \%, 78 \%$ and $65 \%$ respectively. This finding is also consistent with study in middle East, Korea as Rukn SA. et al. ${ }^{36}$ and $\mathrm{Kim}$ et al. ${ }^{37}$ found hypertension as $66 \%$ and $61.1 \%$ respectively. Zafar F. et al. ${ }^{8}$ also found DM as $36.6 \%$ which was also comparable to this study. In this study hypertension was significantly associated in large artery atherosclerosis which is also comparable with Zafar F. et al. ${ }^{8}$.

\section{Conclusion:}

The most common subtype of ischemic stroke in our study was large artery atherosclerosis. Hypertension was significantly high in large artery atherosclerosis group. Among male patients hypertension, diabetes, dyslipidaemia were significantly high.

\section{References:}

1. Katan M, Luft A. Global burden of stroke. SEMIN NEUROL. 2018;38(02):208-11.

2. Adamson J, Beswick A, Ebrahim S. Is stroke the most common cause of disability? J STROKE CEREBROVASC. 2004; 13(4): 171-77.

3. Donkor, Eric S. Stroke in the 21st century: A snapshot of the burden, epidemiology, and 
quality of life. Stroke Reaserch and Treatment [Internet]. 2018 [cited 2020 May 20]. https:// doi.org/10.1155/2018/3238165

4. Feigin VL, Forouzanfar MH, Krishnamurthi R, Mensah GA, Connor M, et al. Global and regional burden of stroke during 1990-2010: findings from the global burden of disease study 2010. Lancet. 2014 jan;18:245-55.

5. Islam MN, Moniruzzaman M, Khalil MI. Burden of stroke in Bangladesh. Int J Stroke. 2013 April;8(3):211-13.

6. Hakan AY, Benner T, Arsava M, Furie KL, Singhal $\mathrm{AB}$ et al. A computerized algorithm for etiologic classification of ischemic Stroke. Stroke. 2007;38:2979-84.

7. Deb P, Sharma S, Hassan KM. Pathophysiologic mechanisms of acute ischemic stroke: An overview with emphasis on therapeutic significance beyond thrombolysis. Pathophysiology. 2010;17:197218.

8. Zafar F, Tariq W, Shoib RF. Shah A, Siddique $\mathrm{M}$, et al. Frequency of ischemic stroke subtypes based on toast classification at a tertiary Care center in Pakistan. Asian J Neurosurg. 2018;13:984-89.

9. Surihan Alharbi A, Saeed Alhayan M, Khalid Alnami S, Traad R.S., Ali Aldawsari M., et al. Epidemiology and risk Factors of stroke. Arch Pharm Pract. 2019;10(4):60-6.

10. Renjen PN, Beg MA, Ahmad K. Epidemiological study of incidence and risk factors of ischemic stroke subtypes according to Trial of ORG 10172 in acute stroke treatment criteria: A 3 years, hospital-based study. INT J MED. Public Health. 2015; 5(1):50-4.

11. Adams HP Jr, Bendixen BH, Kappele LJ, Biller J, Love BB. et al. Classification of subtype of acute ischemic stroke. Definitions for use in a multicenter clinical trial. TOAST. Trial of Org 10172 in acute stroke treatment. Stroke. 1993;24:35-41.
12. Fure B, Wyller TB, Thommessen B. TOAST criteria applied in acut eischemic stroke. Acta Neurol. Scand. 2005;112(4):254-8.

13. Bhowmik NB, Abbas A, Saifuddin M, Islam MR, Habib R, et al. Ischemic Strokes: observations from a hospital based stroke registry in Bangladesh. Stroke Research and Treatment [Internet]. 2016 Sep[Cited 2020 April 13]. https://doi.org/10.1155/2016/ 5610797

14. Shakya D, Shrestha R, Dhungana K, Kafle $\mathrm{R}$, Bhatta S. Ischemic stroke: observations and analysis of stroke patients. Journal of Kathmandu Medical College. 2019;8(2):5571.

15. Caso V, Paciaroni M, Agnell G, Corea F, Ageno W. Gender differences in patients with acute ischemic stroke. Women's Health. 2010;6(1):51-7.

16. Bender M, Jusufovic E, Railic V, Kelava S, Tinjak S, et al. High burden of stroke risk factors in developing country: the case study of Bosnia-Herzegovina. Mater Sociomed. 2017;29(4):277-9.

17. Bouzidi N, Ayadi B, Bouchhima I, Turki E, Damak M. Etiologic epidmiology of ischemic stroke. Neurology. 2016; Poster.

18. Kaul S, Alladi S, Jabeen S, Bandaru R, Ankem $\mathrm{U}$. Intracranial atherosclerosis is the most common stroke subtype: Ten-year data from hyderabad stroke registry (India). ANN INDIAN ACAD NEUR. 2018;21(3):20913.

19. De Silva DA, Woon FP, Lee MP, Chen CP, Chang HM, et al. South Asian patients with ischemic stroke intracranial large arteries are the predominant site of disease. Stroke. 2007;38:2592-4.

20. Harris S, Sungkar S, Rasyid A, Kurniawan M, Mesiano T, et al. TOAST subtypes of ischemic stroke and its risk factors: A hospital-based study at Cipto Mangunkusumo Hospital, Indonesia. Stroke Research and Treatment [Internet]. 2018 [Cited 2020 March 21]. https:/ /doi.org/10.1155/2018/9589831. 
21. Tan YF, Zhan LX, Chen XH, Guo JJ, Qin C. Risk factors, clinical features and prognosis for subtypes of ischemic stroke in a Chinese population. Current Medical Science. 2018;38:296-303.

22. Shubhakaran KP, Bhargava A, Sachdeva K, Kaushal NK. Subtypes of ischemic stroke and their risk factors in western Rajasthan: $A$ Cross sectional study at tertiary centre. EC Neurology. 2019;11(3):166-72.

23. S, Raghuvanshi. A study of clinical proû le and subtypes of acute ischemic stroke in a tertiary care center. Int. J. Sci. Study. 2016;4(5):128-31.

24. Kolominsky-Rabas PL, Weber M, Gefeller O, Neundoerfer B, Heuschmann PU. Epidemiology of ischemic stroke subtypes according to TOAST criteria incidence, recurrence, and long-term survival in ischemic stroke subtypes: A population-based study. Stroke. 2001;32:2735-40.

25. Kang DW, Chalela JA, Ezzeddine MA, Warach S. Association of ischemicl lesion patterns on early diffusion-weighted imaging with TOAST stroke subtypes . Arch Neurol. 2003;60:1730-4.

26. Aquil N, Begum I, Ahmed A, Vohra EA, Soomro BA. Risk Factors in various subtypes of ischemic stroke according to TOAST criteria. JCPSP-J COLL PHYSICI. 2011;21(5):280-3.

27. Murthy Raju VP, Vinayasekhar, Chander T, Srilatha. Categorization of ischemic stroke according to TOAST and ACOS Into various subtypes. Indian J. Appl. Res. 2016;6(10):292-4.

28. Kaul S, Sunitha P, Suvarna A, Meena AK, Uma M. Subtypes of ischemic stroke in a metropolitan city of south India (one year data from a hospital based stroke registry). Neurol. India. 2002;50(Suppl1):S8-14.
29. Biswas M, Sen S, Simmons J. Etiology and risk factors of ischemic stroke in IndianAmerican patients from a hospital-based registry in New Jersey, USA. NEUROL ASIA. 2009;14(2):81-6.

30. Ihle-Hansen H, Thommessen B, Wyller TB, Engedal K, Fure B. Risk factors for and incidence of subtypes of ischemic stroke. FUNCT NEUROL. 2012;27(1):35-40.

31. Wu CY, Wu HM, Lee JD, Weng HH. Stroke risk factors and subtypes in different age groups: A hospital-based study. Neurol. India. 2010;58(6):863-8.

32. Syed NA, Khealani BA, Ali S, Hasan A, Akhtar $\mathrm{N}$, Brohi $\mathrm{H}$, et al. Ischemic stroke subtypes in Pakistan: the Aga Khan University stroke data bank. J PAK MED ASSOC. 2003;53:584-8.

33. Sharif F, Ghulam S,Sharif A. Prevalence of risk factors associated with stroke. Pak Heart J. 2019;52(01):91-5.

34. Taj F, Zahid R, Syeda UR, Murtaza M, Ahmed S. Risk factors of stroke in Pakistan: A dedicated stroke clinic experience. Can. J. Neurol. Sci. 2010;37:252-7.

35. Pathak A, Kumar P, Pandit AK, Chakravarty $\mathrm{K}$, Misra S, et al. Is prevalence of hypertension increasing in first-ever stroke patients?: A hospital-based cross-sectional study. Annals of Neuroscience. 2018;25:219-22.

36. Rukn SA, Mazya MV, Hentati F, Sassi SB, Nabli F. Stroke in the Middle-East and North Africa: A 2-year prospective observational study of stroke characteristics in the regionresults from the safe implementation of treatments in stroke (SITS)-Middle-East and North African (MENA). J STROKE. 2019;14(7):715-22.

37. Kim, Tae K, Doo AJ, Young B, Jaeick J. Current epidemiologic status of stroke. J Korean Acad Rehabil Med. 2003;27(2): 178-85. 